\title{
Prevalence of anemia among adults at Hawassa University referral hospital, Southern Ethiopia
}

\author{
Misganaw Birhaneselassie Mengesha ${ }^{1 *}$ (D) and Gezahegn Bekele Dadi
}

\begin{abstract}
Introduction: Anemia is a public health problem in Ethiopia. In spite of the fact that anemia is a common health burden with much severe consequences, the prevalence of the different types of anemia and its severity have not yet been well documented in different parts of the country. The study aimed to assess the prevalence of different types of anemia, including severity and association with age and sex of study population.

Materials and methods: Four hundred anemic patients who are men and non-pregnant women above 15 years of age were selected from patients visiting the laboratory for Complete Blood Count (CBC) investigation. The type and severity of anemia were assessed based on red cell indices and haemoglobin levels respectively. Data was analyzed using SPSS version 19. Chi square was used at 95\% confidence interval, considering $P<0.05$ statistically significant for association among categorical variables.

Result: The overall prevalence of anemia in the study was 13\%. Majority of cases had mild anemia 58.5\%, while 19.0\%, and $22.5 \%$ of the patients had moderate and severe anemia respectively. Overall, the prevalence of mild anemia increases with age, while the prevalence of moderate and severe anemia decreases as age increases. In the present study, the most common anemia was normocytic, which mostly occur in the elderly (61-85) years of age.

Conclusion: The CBC parameters help to diagnose and classify anemia in to major components, which might help for a better treatment practice in developing countries, where additional investigations are not available for a reliable diagnosis and classification of anemia. Despite resource limitations in developing countries, additional anaemia work up such as iron studies and markers of inflammation, will provide a more efficient diagnosis of anaemia.
\end{abstract}

Keywords: Prevalence, Anemia, Adults, Ethiopia

\section{Introduction}

Globally, anemia affects more than 2 billion people accounting for over a quarter of the world population $[1,2]$. The highest prevalence of anemia exists in the developing world where its causes are multi-factorial. Anemia is responsible for significant morbidity and mortality, particularly in less developed countries. Anemia causes many complications and has been related to reduced work capacity, reduced ability to execute activities of daily living, reduced cognitive function and fatigue among others $[3,4]$.

\footnotetext{
*Correspondence: misganawbs@gmail.com

${ }^{1}$ Department of Medical Laboratory Sciences, Hawassa University College of Medicine and Health Sciences, Hawassa, Ethiopia

Full list of author information is available at the end of the article
}

In Africa, prevalence of anemia is diverse. A study in Uganda reported a prevalence of 16.8 to $33.8 \%$ anemia in adult men and women [5]. Another study also reported anemia in older people, $12.5 \%$ in males and $13.2 \%$ in females in South Africa [6] and 23\% prevalence in Zimbabwe general population [7]. A study from Ghana reported a $53.2 \%$ prevalence of anemia in non-pregnant women [8]. Similar studies have been reported in Ethiopia, 17 to $52.3 \%$ prevalence of anemia [9-11]. In addition, data from WHO indicated prevalence of anemia among non-pregnant women in Ethiopia was $23.3 \%$ as of 2016 . Its highest value over the past 26 years was $47.50 \%$ in 1990 , while its lowest value was $21.40 \%$ in 2012 [12].

Despite the high prevalence and serious consequences of anemia, there have been few reported studies assessing

(c) The Author(s). 2019 Open Access This article is distributed under the terms of the Creative Commons Attribution 4.0 International License (http://creativecommons.org/licenses/by/4.0/), which permits unrestricted use, distribution, and 
the effectiveness of anemia prevention and control programs in developing countries. Prevention and control of anemia is essential to reduce its consequences which further require effective treatment, and management of patients. Likewise, effective diagnosis of anemia is the main avenue for proper treatment and management of anemic patients $[13,14]$.

Even though anemia places a significant burden in many developing nations with much severe consequences, the magnitude of the different types of anemia and its severity have not yet been well documented in different parts of Ethiopia [11, 15]. Therefore, more work ups on anemia are required to produce national data. There is a need to define the current magnitude of anaemia and aim for its reduction. Tackling this problem from the point of its diagnosis and classification for better treatment and management of patients with anemia would be essential.

The works assess the current magnitude of the problems, its severity and categories for ease of diagnosis and monitoring of anemia among clinicians. This data will be required for health planning and preparation of local guidelines or algorithms for diagnosis. It draws knowledge to consider the implications for treatment guidance, and represents epidemiological data on the prevalence of anemia and its different forms. The present study therefore, aims to study the occurrence of different types of anemia in this particular study population.

\section{Materials and methods}

\section{Description of the study}

The study is intended to assess the prevalence of different types of anemia, including severity and association with age and sex of study participants, and other CBC parameters as variables. This study used data from Complete Blood Count $(\mathrm{CBC})$ performed by hematology analyzer (Cell Dyn 1800) to determine the prevalence of different types of anemia treated at the Hawassa University Referral hospital outpatient department (OPD). All the procedures were performed following standard operating procedures and protocol for hematology analyzer.

\section{Study subjects}

The study subjects were patients who visited the laboratory for $\mathrm{CBC}$ investigation, of whom anemic patients were selected to calculate the prevalence and for further investigation on anemia. Those study subjects were sourced from patients visiting the OPDs of the Referral hospital for various clinical examinations. The OPD laboratory of the Referral hospital performs about 30-40 $\mathrm{CBC}$ investigations a day on average. During the data collection period (2016, March/April/May) 3076 CBC were performed, out of which 400 anemic subjects were selected for further analysis and study.

\section{Study design}

Study type: Cross sectional laboratory based study was undertaken on patients visiting the laboratory for $\mathrm{CBC}$ investigation. Sampling procedure: Convenient sampling was used. Every patient with $\mathrm{CBC}$ result was considered daily. Participants were recruited consecutively. Then, patients with anemia were selected and prevalence was calculated from the total patients with $\mathrm{CBC}$ during the study period. Sample size: Using the prevalence formula, $\mathrm{z}^{2} \mathrm{pq} /$ $\mathrm{d}^{2}$ and a maximum $\mathrm{p}$ of 0.5 , the maximum sample size for a cross sectional survey is about 384 at $95 \% \mathrm{CI}$, where normal standard deviation is 1.96 and degree of freedom of $5 \%$. The study however considered a contingency of $5 \%$ which makes the total sample size required about 400 .

\section{Inclusion criteria}

Any patient with anemic result based on the HGB would be involved in the study. Adult men and women who were more than 15 years of age were included in the study. Infants and young children including pregnant women have variable $\mathrm{CBC}$ and other hematological values due to physiological and other conditions and so were excluded. Hence, it was preferred to include adult male and female who are non -pregnant.

\section{Procedure}

Experienced laboratory personnel collected $5 \mathrm{ml}$ of blood sample for CBC. Anemic patients based on HGB result were selected for further analysis of the $\mathrm{CBC}$ values. The $\mathrm{CBC}$ reports were registered [Hemoglobin (HGB), Hematocrit (HCT), Mean Cell Volume (MCV), Mean Cell Hemoglobin ( $\mathrm{MCH})$, Mean Cell Hemoglobin Concentration (MCHC), Red Cell Distribution width (RDW), Red Blood Cell count (RBC count), White Blood Cell (WBC count), Platelet (PLT) and Differential Leukocyte Count] for each patient. The first step in approaching anemia is to classify the process as microcytic (MCV, < $80 \mathrm{fL})$, normocytic (MCV, 80-100 fL), or macrocytic $(\mathrm{MCV},>100 \mathrm{fL})$, which this exercise markedly narrows the differential diagnosis that needs to be considered in each patient [16-18].

Anemia was defined in accordance with World Health Organization (WHO) criteria [19] as a hemoglobin concentration less than $12.0 \mathrm{~g} / \mathrm{dL}$ in women and less than $13.0 \mathrm{~g} / \mathrm{dL}$ in men. Women who had HGB value between 11 and $12 \mathrm{~g} / \mathrm{dL}, 8-11 \mathrm{~g} / \mathrm{dL}$, and $<8 \mathrm{~g} / \mathrm{dL}$ were categorized as having mild, moderate, and severe anemia, respectively. For men anemia $<13.0 \mathrm{~g} / \mathrm{dl}$, mild $11-12 \mathrm{~g} / \mathrm{dl}$, moderate $8-11 \mathrm{~g} / \mathrm{dL}$, and severe $<8 \mathrm{~g} / \mathrm{dl}$ was considered to classify the severity of anemia in this study [20-22].

\section{Ethical consideration}

Ethical clearance was obtained from IRB (Institute Review Board) of Hawassa University College of Medicine 
and Health Sciences. Patient consent was obtained and additional support was sought from the laboratory management of Hawassa University Referral hospital.

\section{Data analysis}

Data was collected in a format prepared for $\mathrm{CBC}$ results, age and sex of patients. Data was entered in to Excel for cleaning, and was analyzed using SPSS version 19. Chi square was used to see statistical association among variables. Statistically significant association among categorical variables was observed at $95 \% \mathrm{CI}, p=0.05$ level of significance.

\section{Result}

A total of 400 anemic patients were considered in the study. Amongst, 58\% were male, and majority were in 15 30 years of age group. The overall prevalence of anemia in the study area was $13 \%$. This study reported, majority of cases had mild anemia $58.5 \%$, while 19.0 and $22.5 \%$ of the patients had moderate and severe anemia respectively. Mild anemia is the highest in both males and females. Moderate anemia is much more common in females than in males. The prevalence of severe anemia, however, is slightly higher in males than in females [Table 1]. The prevalence of mild anemia in the study population is much higher than the prevalence of moderate and severe anemia, and even than the combination of the two (moderate - severe). Overall, the prevalence of mild anemia increases with age, while the prevalence of moderate and severe anemia decreases as age increases (Fig. 1).

Based on the MCV, majority of the anemia $62 \%$ were normocytic while 27 and $11 \%$ of them were microcytic and macrocytic respectively. Whereas, the $\mathrm{MCH}$ and $\mathrm{MCHC}$ values respectively showed 35 and $46 \%$ of the patients had hypochromic anemia. However, $52 \%$ of the anemic subjects had normochromic anemia, equally based on both $\mathrm{MCH}$ and $\mathrm{MCHC}$ values, which is the majority (Table 1). According to the RDW, $81 \%$ of the anemic cases demonstrated an RDW of $>14.0$ which reflects the red cells in those patients showed anisocytosis. In addition, $26 \%$ of the anemic patients had a high WBC count (>10,000/mm3), while $24 \%$ had low WBC count (Table 1).

As depicted in Table-1, most of the anemic subjects showed a normal MCV which reported the most common anemia in the study subjects was normocytic. While the same large group of anemic subjects demonstrated a normal $\mathrm{MCH}(52 \%)$ and $\mathrm{MCHC}$ value (52\%) which similarly reported a normochromic anemia. Accordingly, this study indicated the leading anemia type among the study population was normocytic normochromic. Besides, this study showed $27 \%$ of the study subjects had microcytic anemia

Table 1 Prevalence of mild, moderate and severe anemia by study subject characteristics with $P$ value

\begin{tabular}{|c|c|c|c|c|c|c|c|}
\hline \multicolumn{2}{|c|}{ Study subjects } & \multirow{3}{*}{$\begin{array}{l}N(\%) \\
215(54 \%)\end{array}$} & \multicolumn{3}{|c|}{ Degree of anemia } & \multirow{3}{*}{$\begin{array}{l}p \text {-value } \\
0.038\end{array}$} & \multirow{3}{*}{$\begin{array}{l}95 \% \mathrm{Cl} \\
0.000-0.012\end{array}$} \\
\hline & & & \multirow{2}{*}{$\begin{array}{l}\text { Mild N (\%) } \\
113(52.6)\end{array}$} & \multirow{2}{*}{$\begin{array}{l}\text { Moderate N (\%) } \\
49(22.8)\end{array}$} & \multirow{2}{*}{$\begin{array}{l}\text { Severe N (\%) } \\
53(24.7)\end{array}$} & & \\
\hline Age & $15-30$ & & & & & & \\
\hline & $31-45$ & $95(24 \%)$ & $62(65.3)$ & $14(14.7)$ & $19(20.0)$ & & \\
\hline & $46-60$ & $65(16 \%)$ & $38(58.5)$ & $10(15.4)$ & $17(26.2)$ & & \\
\hline & $61-85$ & $25(6 \%)$ & $21(84.0)$ & $3(12.0)$ & $1(4.0)$ & & \\
\hline \multirow[t]{2}{*}{ Gender } & Female & 168 (42\%) & $89(53.0)$ & $42(25.0)$ & $37(22.0)$ & 0.030 & $0.013-0.047$ \\
\hline & Male & $232(58 \%)$ & $145(62.5)$ & $34(14.7)$ & $53(22.8)$ & & \\
\hline \multirow[t]{3}{*}{ MCV } & $<80.0$ & $109(27 \%)$ & $49(45.0)$ & $32(29.4)$ & $28(25.7)$ & 0.001 & $0.260-0.350$ \\
\hline & $80.0-100.0$ & $248(62 \%)$ & $170(68.5)$ & $39(15.7)$ & $39(15.7)$ & & \\
\hline & $>100.0$ & $43(11 \%)$ & $15(34.9)$ & 5 (11.6) & $23(53.5)$ & & \\
\hline \multirow[t]{3}{*}{$\mathrm{MCH}$} & $<26.0$ & 138 (35\%) & $67(48.6)$ & $39(28.3)$ & $32(23.2)$ & 0.001 & $0.222-0.308$ \\
\hline & $26.0-32.0$ & $208(52 \%)$ & $145(69.7)$ & $28(13.5)$ & $35(16.8)$ & & \\
\hline & $>32.0$ & $54(14 \%)$ & $22(40.7)$ & $9(16.7)$ & $23(42.6)$ & & \\
\hline \multirow[t]{3}{*}{$\mathrm{MCHC}$} & $<31.0$ & $184(46 \%)$ & $96(52.2)$ & $44(23.9)$ & $44(23.9)$ & 0.004 & $0.170-0.250$ \\
\hline & $31.0-36.0$ & 206 (52\%) & $136(66.0)$ & $29(14.1)$ & $41(19.9)$ & & \\
\hline & $>36.0$ & $10(3 \%)$ & $2(20.0)$ & $3(30.0)$ & $5(50.0)$ & & \\
\hline \multirow[t]{2}{*}{ RDW } & $11.0-14.0$ & 74 (19\%) & $61(82.4)$ & $7(9.5)$ & $6(8.1)$ & 0.001 & $0.000-0.007$ \\
\hline & $>14.0$ & $326(82 \%)$ & $173(53.1)$ & $69(21.2)$ & $84(25.8)$ & & \\
\hline \multirow[t]{3}{*}{ WBC } & 5.0 & $96(24 \%)$ & $40(41.7)$ & $135(67.2)$ & $59(57.3)$ & 0.001 & $0.000-0.012$ \\
\hline & $5.0-10.0$ & $201(50 \%)$ & 19 (19.8) & $34(16.9)$ & $23(22.3)$ & & \\
\hline & $>10.0$ & $103(26 \%)$ & $37(38.5)$ & 32 (15.9) & $21(20.4)$ & & \\
\hline
\end{tabular}




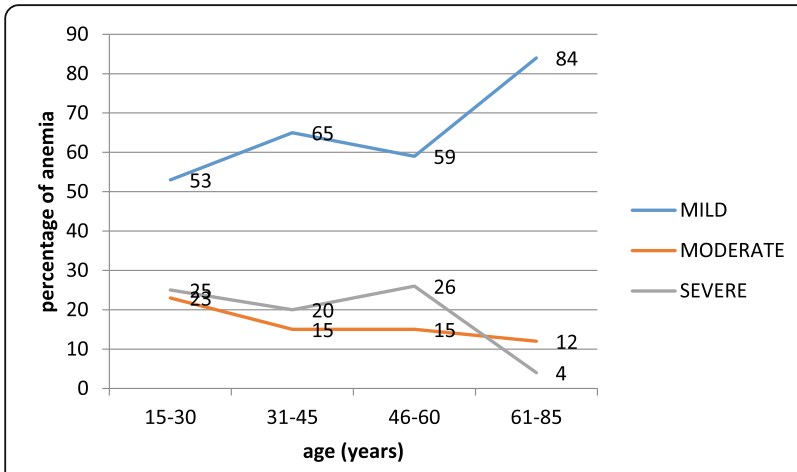

Fig. 1 Prevalence and severity of anemia by age

(MCV < 80fl), also $35 \%$ and $46 \%$ of the study subjects had lower $\mathrm{MCH}$ and $\mathrm{MCHC}$ values which further demonstrated the second most common type of anemia in the study population was hypochromic microcytic. On the other hand, the macrocytic anemia took a lesser proportion among the study group. It showed (11\%) of the study subjects reported an MCV value of more than $100 \mathrm{fl}$ (Table 1).

In mild anemia majority (68.5\%) of the cells are normocytic. In moderate anemia, majority of the cells are microcytic (29.4\%). In severe anemia, most of the cells are macrocytic $54 \%$ [ $p=0.001]$. Similarly, in mild anemia majority of the cells $(70 \%)$ are normochromic. In moderate anemia most $28 \%$ of the cells are hypochromic $[p=0.001]$. RDW is majorly normal in mild anemia (82.4\%), [ $p=0.001]$ (Table 1). The RDW demonstrated highest when the red cells are microcytic (RDW=96.3\%) and macrocytic (RDW=88.4\%). Similarly, the RDW showed highest result when the red cells are hypochromic (RDW=98\%), (Table 1).

In the present study, the most common anemia was normocytic, which mostly occur in the elderly (61-85) years of age. Microcytic and macrocytic anemias occur more often in younger age group of subjects. In any age group the prevalence of normocytic anemia is higher than microcytic and macrocytic. Prevalence of normocytic anemia increases as age increases. While the second most prevalent anemia microcytic anemia decreases as age increases [ $p=0.001]$, (Fig 2).

\section{Discussion}

This study registered an overall anemia prevalence of 13 $\%$ in the study population. This is considered a minor public health problem according to WHO/CDC classification [23]. This prevalence is much lower than the $30.4 \%$ found in the study of Haider performed in nine regional states of Ethiopia in 2010 [11]. Studies in South Africa reported a comparable result $12.6 \%$ [24] and $17.5 \%$ [25]. A study in Malawi reported a prevalence of anemia in the study population was $16.2 \%$ [20]. Adewoyin also reported a $27.3 \%$ of anemia in a University

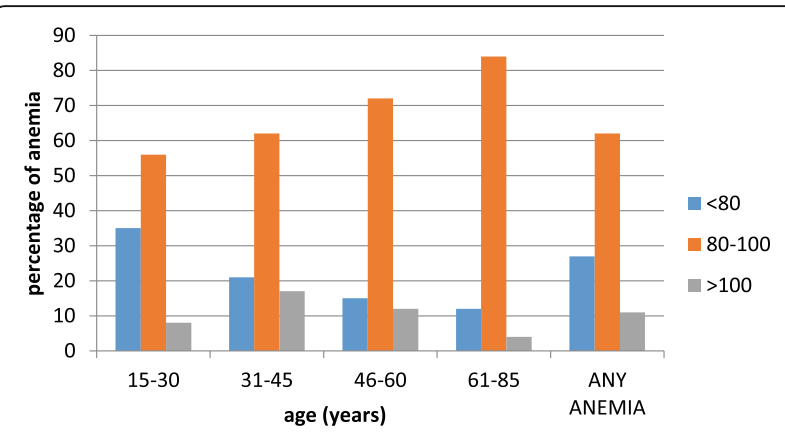

Fig. 2 Prevalence of normocytic, normochromic and macrocytic anemia by age

Teaching hospital from Nigeria [26]. Prevalence of anemia infact depends on many features such as age, gender, pregnancy, and other related factors. The sampling method used in this study might also have contributed to a lower prevalence of anemia, where the study population included in the study were not specifically diagnosed for having anemia clinically, however, any patient with $\mathrm{CBC}$ for any clinical investigation were included in the survey. This is similar with the study from Adewoyin which reported a $12 \%$ prevalence of anemia in out-patients. It was further noted that the prevalence of anemia among hospitalized patients is found to be significantly higher compared to out- patients $[26,27]$ that another factor for the stated prevalence of anemia in the present study could be the subjects were from out-patient departments.

As indicated in the present study the leading anemia was normocytic normochromic. Similar studies reported a high proportion of normocytic anemia; a study in Italy and Brazil reported $88 \%$ and $72.3 \%$ cases of normocytic anemia [27, 28], another study also reported a $46 \%$ prevalence of normocytic normochromic anemia as the most common type of anemia [29]. On the contrary, other studies reported the vast majority of anemia cases were microcytic, which is the second most prevalent anemia in this study $[22,30]$. The present study also showed $11 \%$ of macrocytic anemia. In comparison a study reported $1.7 \%$ to $3.6 \%$ macrocytic anemia [31], this study showed there is a higher proportion of macrocytic anemia in the study population than in other studies which needs to be further investigated to identify a possible reason of macrocytic anemia in the study area. Normochromic normocytic anemia dominate through any age group, hypochromic microcytic and macrocytic anemias occur more often in younger age group of subjects, $[p=0.001]$. Studies have shown microcytic and hypochromic anemia more often associated with iron deficiency anemia, but there can be more likely causes for it [32]. Likewise, from the survey based on the higher level of microcytic anemia in the younger patients 
compared to older patients, it is assumed that IDA is more common in younger patients.

Mild anemia is the most common type in the present study, and severe anemia is more common than moderate anemia. This finding was similar with a study from Nigeria which reported most cases of anemia observed were mild in severity and that $14.9 \%$ of all anemic patients had severe form of anemia [26]. Among the age groups, most of the anemia (54\%) occurs in the 15-30 years group and the least (6\%) prevalent anemia is found in the elderly who are 61-85 years old patients. Other studies have reported $11.8 \%, 5.4 \%$ and 8 to $44 \%$ prevalence of anemia in the elderly which is comparable with our finding $[27,33,34]$. The present study showed mild anemia increases with age and mild anemia affects one out of sixteen elderly individuals.

Similar figures have been reported in other studies [35, 36]. Anemia in the elderly might be considered as a normal consequence of aging, and treatment might be ignored for the true cause of anemia. Other studies have indicated ACD (anemia of chronic disease) is the most common form of anemia in the elderly [37, 38]. Besides, as mild anemia is the most frequent anemia in this study the possible causes underneath need to be investigated including the young age group. Moderate and severe anemia constitutes $40 \%$ of the anemia in the survey. These forms of anemia are common in the 15-30 young age group, which affects the productive age group in the society. These group of anemic patients should get attention as they affect patients much more than the mild form of anemia. A great proportion of the moderate and severe anemia belong to the microcytic and macrocytic form of anemia.

In addition, most of severe anemia associated with macrocytic anemia, vise versa; in macrocytic

anemia most of the cases of anemia are severe. In this study severe anemia was found to be more prevalent than moderate anemia. The study from Nigeria however reported moderate anemia is more common than severe anemia unlike this study [26]. Another study reported severe anemia was rare, there being only 22 cases for a prevalence of $0.3 \%$ [27]. A study in southern Ethiopia also reported there was no severe anemia among pregnant women [39]. This study however, reported a higher proportion of macrocytic anemia in relation to other studies which should get an attention for its possible causes. The occurrence of a higher proportion of macrocytosis can be due to presence of spherocytosis, due to folate and vitamin B12 deficiency and other reasons. Moreover, this study elucidated macrocytic anemia is largely associated with leukopenia. In leukopenic patients $25 \%$ of the cells are macrocytic, unlike $6 \%$ in leukocytosis and normal white blood cell patients $[p=0.004]$. This additionally suggests the possibility that this group of patients might have vitamin B12/Folate deficiency as significant leukopenia is a laboratory feature in megaloblastic anemia.

The RDW value was very high throughout the sample measurements that $(82 \%)$ of the samples

demonstrated a higher than normal RDW (>14.0). The highest RDW was registered in hypochromic anemias $96 \%$, and $88 \%$ of macrocytic anemia, than in normocytic anemia $74 \%,[P=0.001]$. This study demonstrated the prevalence and severity of anemia is associated with RDW measurement, and severe anemia is associated with a higher degree of anisocytosis. Another study also suggested, MCV should be used together with the RDW, thus directing the interpretation of the variation in the size of red blood cells and hence anemias [40, 41].

Roughly, the CBC report helped in classification of anemia in to three major components. The study also showed these entities of anemia occur in the OPDs of the Referral hospital from the surrounding community. The $\mathrm{CBC}$ is not quite suffice to properly identify and reach to a more accurate and precise diagnosis of anemias, but it is still useful to use the $\mathrm{CBC}$ for diagnosis and classification of anemia. Additional investigations remain required for proper diagnosis, treatment and management of anemia in developing countries. The iron-panel tests such as Ferritin, Vitamin B12, Folate and the like are fundamental investigations to be carried out for prompt diagnosis and classification of anemia.

\section{Conclusion}

The prevalence of anemia in the study group was considerable. The study identified different types of anemia in good prevalence in the area. The CBC help to diagnose and classify anemia in to major components, which help for a better treatment practice in developing countries, where resources are limited. However, it does not able to diagnose and confirm other entities of anemia, and hence additional investigation methods are essential for efficient diagnosis and classification of anemia, and thus for better management and monitoring of anemic patients.

\section{Abbreviations \\ CBC: Complete Blood Count; CDC: Center for Disease Control; \\ HCT: Hematocrit; HGB: Hemoglobin; IRB: Institute Review Board; MCH: Mean Cell Hemoglobin; MCHC: Mean Cell Hemoglobin Concentration; MCV: Mean Cell Volume; OPD: Outpatient Department; PLT: Platelet; RBC count: Red Blood Cell count; RDW: Red Cell Distribution Width; WBC count: White Blood Cell; WHO: World Health Organization}

\section{Acknowledgements}

We acknowledge the Hawassa University for support and encouragement of this research. We also thank the OMICS $11^{\text {th }}$ international conference to present this work.

\section{Funding}

The Hawassa University supported the research in the design of the study. The authors carried out the collection, analysis, and interpretation of data and writing the manuscript. 


\section{Availability of data and materials}

The datasets generated and analysed during the current study are available from the corresponding author on reasonable request.

\section{Authors' contribution}

MB: proposal design, data analysis, Interpretation, write up. GB: proposal design, data analysis and write up. All authors read and approved the final draft of the manuscript.

\section{Competing interest}

The authors declared that they have no competing interest.

\section{Ethics approval and consent to participate}

Ethical clearance was obtained from IRB (Institute Review Board) of Hawass University College of Medicine and Health Sciences. Initially, verbal consent was obtained from all patients visiting the laboratory for $C B C$ regardless of their HGB result. Anemic patients' data was collected from hematology analyzer after the patients have left the OPDs of the Referral hospital. It was not convenient to find the patients as they left the hospital after treatment, which the ethics committee approved this form of consent. The study included adult men and women who were more than 15 years of age and hence the patients were directly requested for consent. Moreover, additional support was sought from the laboratory management of Hawassa University Referral hospital.

\section{Consent for publication}

Not applicable. Both authors read and approved to publish the research.

\section{Publisher's Note}

Springer Nature remains neutral with regard to jurisdictional claims in published maps and institutional affiliations.

\section{Author details}

${ }^{1}$ Department of Medical Laboratory Sciences, Hawassa University College of Medicine and Health Sciences, Hawassa, Ethiopia. ${ }^{2}$ School of Nursing and Midwifery, Hawassa University College of Medicine and Health Sciences, Hawassa, Ethiopia.

\section{Received: 14 December 2017 Accepted: 10 December 2018}

\section{Published online: 08 January 2019}

\section{References}

1. McLean E, Cogswell M, Egli I, Wojdyla D, de Benoist B. Worldwide prevalence of anaemia, WHO vitamin and mineral nutrition information system, 1993-2005. Public Health Nutr. 2009;12(4):444-5.

2. Pasricha SR. Anemia: a comprehensive global estimate. Blood. 2014;123(5): 611-2.

3. Tolentino K, Friedman JF. An update on anemia in less developed countries. Am J Trop Med Hyg. 2007;77(1):44-51.

4. Prasanth R. Prevalence of anemia in both developing and developed countries around the world. World J Anemia. 2017;1(2):40-3.

5. Mugisha JO, Baisley K, Asiki G, Seeley J, Kuper H. Prevalence, types, risk factors and clinical correlates of Anaemia in older people in a rural Ugandan population. PLoS One. 2013;8:10.

6. Oldewage-Theron WH, Samuel F, Grobler C, Egal A. Anaemia prevalence and dietary intake of elderly persons living in a peri-urban settlement in South Africa. Journal of Family Ecology and Consumer Sciences. 2008;36:22-9.

7. Allain TJ, Gomo Z, Wilson AO, Ndemera B, Adamchak DJ, et al. Anaemia, macrocytosis, vitamin B 12 and folate levels in elderly Zimbabweans. Cent Afr J Med. 1997:43:325-7.

8. Samuel TCK, Agboli E, Hoffman H, Walana W. Malaria and anemia in pregnant and non-pregnant women of child-bearing age at the university hospital, Kumasi, Ghana. Open J Med Microbiology. 2013;3:3.

9. WHO/CDC. Worldwide Prevalence of Anemia, vol. 1993-2005. Switzerland: WHO Global Database on Anemia, World Health Organization, Geneva; 2008.

10. Central Statistical Agency and ICF Macro, Ethiopia Demographic and Health Survey Preliminary Report, Central Statistical Agency, Addis Ababa, Ethiopia; ICF Macro, Calverton, Md, USA, 2011.

11. Haidar J. Prevalence of anaemia, deficiencies of iron and folic acid and their determinants in Ethiopian women. J Health Popul Nutr. 2010;28(4):359-68.
12. World Health Organization, Global Health Observatory Data Repository/ World Health Statistics (http://apps.who.int/gho/data/node.main.1?lang=en).

13. Iron deficiency anaemia WHO/UNICEF/UNU. Assessment, prevention, and control. Geneva: World Health Organization; 2001.

14. WHO, UNICEF, UNU. Iron deficiency Anaemia: assessment, Prevention and Control, A Guide for Programme Managers, WHO, UNICEF, UNU, Geneva, Switzerland, 2001.http://www.who.int/nutrition/publications/micronutrients/ anaemia_iron_deficiency/WHO_NHD_01.3/en/index.html.

15. Betelihem T, Asaye B, Paulos N, Aster T. Effect of Maternal Iron Deficiency Anemia on the Iron Store of Newborns in Ethiopia; 2015. p. 6.

16. Tefferi A. Anemia in adults: a contemporary approach to diagnosis. Mayo Clin Proc. 2003;78:1274-80.

17. Tefferi A. Practical algorithms in anemia diagnosis [letter]. Mayo Clin Proc. 2004;79:955-6.

18. Ayalew T, Curtis A, Hanson DJ. Inwards. How to Interpret and Pursue an Abnormal complete blood cell count in adults. Mayo Clin Proc. 2005;80(7): 923-36.

19. World Health Organization Nutritional Anemia. Report of a WHO scientific group. Tech Rep Ser. 1968:405:1-40

20. Aishatu L, Adamu L, Amelia C, Ndoliwe K, Alemayehu A, Olivier K, Amos P, et al. Prevalence and risk factors for anemia severity and type in Malawian men and women: urban and rural differences. Popul Health Metrics. 2017;15:12.

21. Yaregal A, TilahunY LG. Determinant factors of Anemia among nonpregnant women of childbearing age in Southwest Ethiopia: a community based study. Hindawi Publishing Corporation International Scholarly Research Notices; 2014. p. 8

22. Gerardo AU, Praveen KN, Manoranjan M, Pradeep SY, Raghavakalyan P. Prevalence and Severity of Anaemia Stratified by Age and Gender in Rural India. Hindawi Publishing Corporation Anemia Volume; 2014. p. 5.

23. World Health Organization, Centers for Disease Control and Prevention. Assessing the Iron status of populations. Geneva: World Health Organisation; 2007.

24. Phatlhane DV, Zemlin AE, Matsha TE, Hoffmann M, Naidoo N, Ichihara K et al. The iron status of a healthy south African adult population. Clin Chim Acta. 2016;460:240-5.

25. Shisana O, Labadarios D, Rehle T, Simbayi I, Zuma K, Dhansay A, et al. South Afican National Health and nutrition examination survey (SANHANES-1). Cape Town: HSRC Press; 2013.

26. Adewoyin AS, Bazuaye GN, Enabudoso E. Burden of anaemia among In- and Out-Patients at the University of Benin Teaching Hospital, Benin City, Nigeria. Annals of Tropical Pathology. 2014;5:2.

27. Mauro T, Ugo L, Francesca G, Angela R, Paola M, Giovanni A, et al. Prevalence, incidence and types of mild anemia in the elderly: the "health and Anemia" population-based study. Haematologica. 2010;95(11).

28. Calleraa F, Calleraa AF, da Silvab AM, Rosaa ES. Prevalence of anemia in a sample of elderly southeastern Brazilians. Rev Bras Hematol Hemoter. 2015; 37(1):43-7.

29. Sgnaolin V, Engroff P, Ely LS, Schneider RH, Schwanke CH, Gomes I, et al. Hematological parameters and prevalence of anemia among free-living elderly in South Brazil. Rev Bras Hematol Hemoter. 2013;35(2):115-8.

30. Guralnik JM, Ershler WB, Schrier SL, Picozzi VJ. Anemia in the elderly: a public health crisis in hematology. Hematology Am Soc Hematol Educ Program. 2005:528-32.

31. Florence Aslinia MD, Mazza JJ, MD MACP, Yale SH, MD, FACP. Megaloblastic Anemia and other causes of Macrocytosis. Clinical Medicine \& Research Volume 4. 3:236-41.

32. Johnson-Wimbley TD, Graham DY. Diagnosis and management of iron deficiency anemia in the 21st century. Ther Adv Gastroenterol. 2011;4(3): 177184.

33. Beutler $E$, Waalen J. The definition of anemia: what is the lower limit of normal of the blood hemoglobin concentration? Blood. 2006;107(5):1747-50.

34. Ania BJ, Suman VJ, Fairbanks VF, Melton $\sqcup \mathrm{III}$. Prevalence of anemia in medical practice: community versus referral patients. Mayo Clin Proc. 1994;69:730-5.

35. Salive ME, Cornoni-Huntley J, Guralnik JM, Phillips CL, Wallace RB, Ostfeld $\mathrm{AM}$, et al. Anemia and hemoglobin levels in older persons: relationship with age, gender, and health status. J Am Geriatr Soc. 1992;40:489-96.

36. Daly MP. Anemia in the elderly. Am Fam Physician. 1989:39:129-36

37. Lipschitz DA. The anemia of chronic disease. J Am Geriatr Soc. 1990;38:1258-64.

38. Cash JM, Sears DA. The anemia of chronic disease: spectrum of associated diseases in a series of unselected hospitalized patients. Am J Med. 1989:87: $638-44$. 
39. Lebso M, Anato A, Loha E. Prevalence of anemia and associated factors among pregnant women in southern Ethiopia: a community based crosssectional study. PLoS One. 2017;12(12).

40. Brittenham GM, Koepke JA. Red blood cell volume distributions and the diagnosis of anemia: help or hindrance? Arch Pathol Lab Med. 1987;13:1146-8.

41. Saxena S, Weiner JM, Carmel R. Red cell distribution width in untreated pernicious anemia. Am J Clin Pathol. 1988;89:660-3.

Ready to submit your research? Choose BMC and benefit from:

- fast, convenient online submission

- thorough peer review by experienced researchers in your field

- rapid publication on acceptance

- support for research data, including large and complex data types

- gold Open Access which fosters wider collaboration and increased citations

- maximum visibility for your research: over $100 \mathrm{M}$ website views per year

At BMC, research is always in progress.

Learn more biomedcentral.com/submissions 